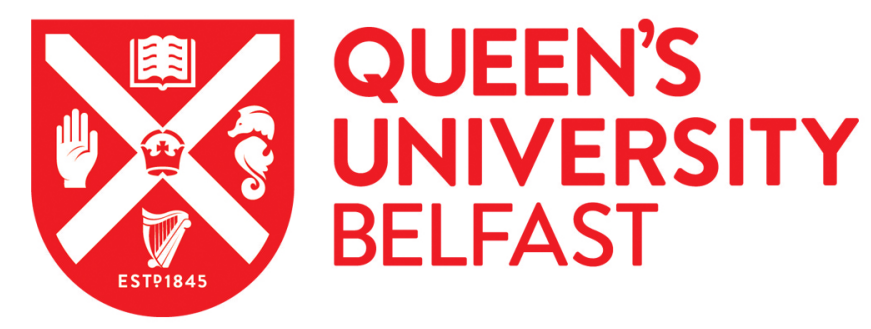

\title{
Self-reports of psychosocial functioning among children and young adults with cleft lip and palate
}

Hunt, O., Burden, D., Hepper, P., Stevenson, M., \& Johnston, C. (2006). Self-reports of psychosocial functioning among children and young adults with cleft lip and palate. The Cleft Palate-Craniofacial Journal, 43(5), 598-605. https://doi.org/10.1597/05-080

\section{Published in:}

The Cleft Palate-Craniofacial Journal

Queen's University Belfast - Research Portal:

Link to publication record in Queen's University Belfast Research Portal

\section{General rights}

Copyright for the publications made accessible via the Queen's University Belfast Research Portal is retained by the author(s) and / or other copyright owners and it is a condition of accessing these publications that users recognise and abide by the legal requirements associated with these rights.

Take down policy

The Research Portal is Queen's institutional repository that provides access to Queen's research output. Every effort has been made to ensure that content in the Research Portal does not infringe any person's rights, or applicable UK laws. If you discover content in the Research Portal that you believe breaches copyright or violates any law, please contact openaccess@qub.ac.uk. 


\title{
Self-Reports of Psychosocial Functioning Among Children and Young Adults With Cleft Lip and Palate
}

\author{
Orlagh Hunt, Ph.D., M.Sc., B.Sc., Donald Burden, Ph.D., M.Sc., B.D.S., F.D.S.R.C.P.S., F.F.D.R.C.S.I., \\ F.D.S.R.C.S., D.Orth.R.C.S., M.Orth.R.C.S., Peter Hepper, Ph.D., B.Sc., C.Psychol. F.B.Ps.S., Mike Stevenson, \\ B.Sc., F.S.S., Chris Johnston, Ph.D., B.Sc., B.D.S., M.Orth.R.C.S. Ed., F.D.S.(Orth.)R.C.S.Ed.
}

\begin{abstract}
Objective: A cross-sectional study was employed to determine the psychosocial effects of cleft lip and/or palate among children and young adults, compared with a control group of children and young adults without cleft lip and palate.

Participants: The study comprised 160 children and young adults with cleft lip and/or palate and 113 children and young adults without cleft lip and/or palate. All participants were between 8 and 21 years of age.

Outcome measures: Psychological functioning (anxiety, self-esteem, depression, and behavioral problems) was assessed using validated psychological questionnaires. Happiness with facial appearance was rated using a visual analog scale. Social functioning, including experience of teasing/bullying and satisfaction with speech, was assessed using a semistructured interview.

Results: Participants with cleft lip and/or palate reported greater behavioral problems $(p<.001)$ and more symptoms of depression $(p<.01)$; they were teased more often $(p<.001)$ and were less happy with their facial appearance $(p<.01)$ and speech $(p<.001)$, compared with controls. There were no significant difference between subjects with cleft lip and/or palate and subjects without cleft lip and/or palate in terms of anxiety $(p>.05)$ or self-esteem $(p>$ .05). Having been teased was a significant predictor of poor psychological functioning, more so than having a cleft lip and/or palate per se $(p<.001)$.

Conclusions: Teasing was greater among participants who had cleft lip and/ or palate and it was a significant predictor of poorer psychosocial functioning. Children and young adults with cleft lip and/or palate require psychological assessment, specifically focusing on their experience of teasing, as part of their routine cleft care.
\end{abstract}

KEY WORDS: cleft, psychosocial, teasing

The general assumption has been made that those with cleft lip and/or palate (CLP) must experience psychosocial problems as a result of their condition. A large body of literature has been published that examines the psychosocial implications of cleft lip and palate. However, a systematic review of the literature has revealed a lack of consensus, with many stud-

\footnotetext{
Dr. Hunt is Lecturer, School of Dentistry, Queen's University Belfast, Belfast, Northern Ireland. Dr. Burden is Senior Lecturer and Consultant Orthodontist, School of Dentistry, Queen's University Belfast, Belfast, Northern Ireland. Dr. Hepper is Professor, School of Psychology, Queen's University Belfast, Belfast, Northern Ireland. Dr. Stevenson is Senior Statistician, Clinical Research Support Centre, Royal Group of Hospitals Trust, Belfast, Northern Ireland. Dr. Johnston is Senior Lecturer and Consultant Orthodontist, School of Dentistry, Queen's University Belfast, Belfast, Northern Ireland.

This study was funded by the Research and Development Office, Northern Ireland Department of Health, Social Services and Public Safety.

Submitted May 2005; Accepted November 2005.

Address correspondence to: Orlagh Hunt, Ph.D., School of Dentistry, Queen's University Belfast, Grosvenor Road, Belfast BT12 6BP, Northern Ireland. E-mail o.hunt@qub.ac.uk.
}

ies producing contradictory evidence on the psychosocial effects of CLP (Hunt et al., 2005).

At a superficial level, the literature suggests that an individual's psychosocial well-being is not affected greatly by CLP (Wirls and Plotkin, 1971; Richman, 1983; Heller et al., 1985; Geier and Wittstock, 1986; Bjornsson and Agustsdottir, 1987; Bressman et al., 1999). However, much of the previous literature has tended to report the psychosocial functioning of CLP children in a general way. When researchers have examined specific aspects of psychological functioning, they have identified behavioral problems (Harper and Richman, 1978; Richman and Millard, 1997), social problems (McWilliams and Paradise, 1973; Peter and Chinsky, 1974), anxiety and depression (Ramstad et al., 1995), and dissatisfaction with facial appearance (Marcusson et al., 2001, 2002). Although these findings are interesting, many of the studies did not use a control group and in some cases did not include the self-report of the individual with CLP, instead relying on the opinion of a parent or a health professional. In addition, many previous studies have measured a single psychological construct and have used 
TABLE 1 Details of study participants

\begin{tabular}{lcc}
\hline & Test group & Control group \\
\hline Sample size & $\mathrm{n}=160$ & $\mathrm{n}=113$ \\
Age & 8 to $21 \mathrm{y}$ & 8 to $21 \mathrm{y}$ \\
Gender & & \\
Male & $104(65 \%)$ & $51(45 \%)$ \\
Female & $56(35 \%)$ & $62(55 \%)$ \\
Visibility of cleft & & - \\
Visible (involves lip) & $102(64 \%)$ & - \\
Not visible & $58(36 \%)$ & - \\
Previous family history of cleft lip and/or palate & \\
Yes & $49(8 \%)$ & $113(100 \%)$ \\
No & $111(69 \%)$ & \\
\hline
\end{tabular}

the results from this to generalize about the subjects' overall psychosocial functioning.

The aim of the present study was to determine whether individuals with CLP have poorer psychosocial functioning, compared with individuals who do not have CLP, by investigating self-reports across a number of areas of psychosocial functioning.

\section{METHODS}

\section{Participants}

One hundred and sixty children and young adults with CLP took part in the study (mean age, 13.6 years). One hundred and thirteen children and young adults who did not have CLP acted as controls (mean age, 13.0 years). Table 1 provides details of the study participants.

Only participants between 8 and 21 years of age, inclusive, at the time of the study were included. The lower age limit of 8 years was selected because participants younger than this would have difficulty completing the measures used in the study. Participant recruitment took place in a hospital setting, therefore an upper age limit of 21 years was chosen, because most patients with CLP are discharged from clinical review beyond this age.

Participants with CLP were recruited from the three main Hospital Orthodontic Departments in Northern Ireland. Only children and young adults with a repaired nonsyndromic CLP and who did not have a learning disability or any other significant medical history were included. Participants for the control group were recruited from a wide range of sources by circulating requests among parents who were members of university and hospital staff and parents attending for hospital appointments. These parents then indicated to the research team if they had a son or daughter age 8 to 21 years who would be willing to participate. Participants were included in the control group only if they did not have CLP, a learning disability, or a significant medical history.

Psychosocial functioning was assessed using a variety of methods, including validated psychological questionnaires, a visual analog scale, and a semistructured interview.

\section{Psychological Functioning}

A number of standardized instruments were used to assess psychological functioning. With a goal of assessing psychological functioning across a wide age range ( 8 to 21 years), it was not possible to have all participants complete the same questionnaire. Different instruments were needed to measure the same aspect of psychological functioning, depending on the participant's age and whether he or she was attending school at the time of the study. Table 2 outlines the questionnaires that were administered and the age group to which they related. All of the questionnaires were validated measures, and therefore it was assumed that they did in fact measure what they purported to measure. Four key psychological constructs were assessed: anxiety, depression, self-esteem, and behavioral problems.

\section{Anxiety}

Participants completed the State Trait Anxiety Inventory (STAI) or the State Trait Anxiety Inventory for Children (STAIC). The STAI (Speilberger, 1983) consists of two parts: state anxiety (20 items) and trait anxiety (20 items). It was completed by participants in the study who were 13 years and older. State anxiety is a transitory emotional state that is characterized by subjective feelings of tension and apprehension in situations perceived as threatening. State anxiety may fluctuate over time and can vary in intensity. Trait anxiety refers to relatively stable individual differences in anxiety (i.e., differences between people in their tendency to perceive stressful situations as dangerous or threatening and to respond to such situations with elevations in the intensity of their state anxiety). The STAIC also consists of 20 items of state anxiety and 20

TABLE 2 Number of participants completing each standardized questionnaire

\begin{tabular}{|c|c|c|c|c|c|c|}
\hline Measure & Questionnaire & Age (y) & School-related & $C L P$ & Control & Total \\
\hline \multirow[t]{2}{*}{ Anxiety } & State Trait Anxiety Inventory for Children (STAIC) & $8+$ & No & 61 & 56 & 117 \\
\hline & State Trait Anxiety Inventory (STAI) & $13+$ & No & 97 & 57 & 154 \\
\hline \multirow[t]{2}{*}{ Depression } & Children's Depression Inventory (CDI) & $8+$ & Yes & 125 & 95 & 220 \\
\hline & Beck Depression Inventory (BDI) & $16+$ & No & 33 & 18 & 51 \\
\hline \multirow[t]{2}{*}{ Self-esteem } & Self-Esteem Index (SEI) & $8+$ & Yes & 128 & 96 & 224 \\
\hline & Rosenberg Self-Esteem Scale (RSE) & $16+$ & No & 30 & 17 & 47 \\
\hline \multirow[t]{2}{*}{ Behavioral problems } & Youth Self-Report (YSR) & $11+$ & Yes & 96 & 62 & 158 \\
\hline & Young Adult Self-Report (YASR) & $18+$ & No & 24 & 15 & 39 \\
\hline
\end{tabular}


items of trait anxiety (Speilberger, 1973). It was completed by children in the study ages 12 years or younger.

\section{Depression}

Participants completed the Beck Depression Inventory (BDI) or the Children's Depression Inventory (CDI). The BDI (Beck et al., 1996) is a 21-item self-report instrument for measuring the severity of depression. In this study it was administered to those participants who were age 16 and older and not attending school and to those participants who were age 18 and older and still in school. The BDI is one of the most widely accepted instruments for assessing the severity of depression in diagnosed patients and for detecting possible depression in normal populations. The CDI (Kovacs, 1992) is a 27-item self-rated scale suitable to assess symptoms of depression in school-age children and adolescents. It was administered to participants age 17 years and younger who were still attending school.

\section{Self-esteem}

Participants completed the Rosenberg Self-Esteem Scale (RSE) or the Self-Esteem Index (SEI). The Rosenberg SelfEsteem Scale (Rosenberg, 1989) was originally developed to measure adolescents' global feelings of self-worth or self-acceptance and is generally considered the standard against which other measures of self-esteem are compared. The RSE was administered to participants older than 16 years of age who were not attending school. The Self-Esteem Index (Brown and Alexander, 1991) is an 80-item self-report instrument designed to elicit children's perceptions of their personal traits and characteristics. The SEI was administered to participants 18 years of age and older who were still attending school.

\section{Behavioral Problems}

Participants who were age 11 and older also completed the problem scales of the Youth Self-Report (YSR) or the problem scales of the Young Adult Self-Report (YASR) to assess potential behavioral problems, depending on their age. In completing the YSR Problem Scales (Achenbach, 1991), the young person rates 112 items in relation to his or her current or previous (last 6 months) experiences. The YSR was administered to those participants between 11 and 18 years of age and who still attended school. The YASR (Achenbach, 1997) assesses 115 behavioral problems and socially desirable characteristics. The YASR was administered to those young people taking part who were age 18 years and older and who were not attending school. No equivalent self-report instrument to assess behavioral problems was available for participants younger than 11 years of age. Two participants with CLP did not complete the questionnaires.

\section{Happiness with Facial Appearance}

The participant's happiness with his or her facial appearance was assessed using a 100-mm visual scale anchored at each end with the words "very unhappy" and "very happy." Participants were asked to mark the scale at the point that best described their happiness with their facial appearance.

\section{Social Functioning}

All of the participants took part in a semistructured interview that addressed eight key areas: sports, clubs and hobbies, home life, school experiences, friendships, relationships with the opposite sex, satisfaction with appearance, satisfaction with speech, and expectations for the future. For the purposes of this paper, only interview data that were binomial in nature (i.e., involved yes or no answers) were included in the analysis. This related to questions about teasing, satisfaction with appearance, and satisfaction with speech. In terms of teasing, subjects were asked if they had ever been teased/bullied, the nature of the teasing/bullying, and why they were teased/bullied. Teasing/bullying was recorded as problematic if the young person reported that it caused him or her significant upset. Teasing/bullying ranged from hurtful teasing to physical violence.

To assess participants' satisfaction with appearance, they were asked what feature(s), if any, they disliked about their appearance and whether they desired a change in their appearance. In terms of satisfaction with speech, subjects were asked if they were satisfied or dissatisfied with their speech in general.

Details of each subject's socioeconomic status (i.e., postcode, which is a commonly employed measure derived from area of domicile) and his or her position in the family (i.e., first born, youngest, only child) were recorded. For subjects in the test group, details also were recorded as to whether there was a previous family history of CLP. A previous history of CLP was noted if the subject had a parent, sibling, grandparent, first cousin, aunt, or uncle with any type of CLP.

Ethical approval for the study was granted by the Research Ethics Committee at Queen's University Belfast and indemnity was provided by the Royal Group of Hospitals, Belfast. Written informed consent was obtained from all participants and/ or their parents, depending on the participant's age.

\section{Statistical Methods}

Analysis of variance (ANOVA), linear regression analysis, and logistic regression analysis were used, where appropriate, to analyze the questionnaire data. Visual analog scales were analyzed using independent samples $t$ tests. Descriptive statistics are presented for the data arising from the interviews. Odds ratios (OR) and confidence intervals $(\mathrm{CI})$ were calculated to establish whether differences existed between the two groups. 
TABLE 3 Mean values and standard deviations (SD) for standardized questionnaires

\begin{tabular}{|c|c|c|c|c|c|c|}
\hline & Measure & Group & $n$ & Mean & $S D$ & $p<.05$ \\
\hline \multirow[t]{8}{*}{ Anxiety } & STAIC & CLP & 61 & 26.7 & 4.8 & $>.05$ \\
\hline & (State) & Control & 56 & 25.4 & 3.5 & \\
\hline & STAIC & CLP & 61 & 28.3 & 5.5 & $>.05$ \\
\hline & (Trait) & Control & 56 & 28.2 & 5.9 & \\
\hline & STAI & CLP & 97 & 30.9 & 10.5 & $>.05$ \\
\hline & (State) & Control & 57 & 30.1 & 6.9 & \\
\hline & STAI & CLP & 97 & 32.9 & 11.2 & $>.05$ \\
\hline & (Trait) & Control & 57 & 33.9 & 8.9 & \\
\hline \multirow[t]{4}{*}{ Depression } & CDI & CLP & 125 & 1.7 & 1.2 & $<.01$ \\
\hline & & Control & 95 & 1.1 & 1.2 & \\
\hline & BDI & CLP & 33 & 1.9 & 1.9 & $>.05$ \\
\hline & & Control & 18 & 2.5 & 1.2 & \\
\hline \multirow[t]{4}{*}{ Self-esteem } & SEI & CLP & 128 & 268 & 23.7 & $>.05$ \\
\hline & & Control & 96 & 265 & 21.6 & \\
\hline & RSE & CLP & 30 & 21.1 & 5.9 & $>.05$ \\
\hline & & Control & 17 & 20.6 & 4.1 & \\
\hline \multirow[t]{4}{*}{ Behavior } & YSR & CLP & 96 & 5.0 & 1.5 & $<.001$ \\
\hline & & Control & 62 & 3.8 & 2.1 & \\
\hline & YASR & CLP & 24 & 5.6 & 2.6 & $>.05$ \\
\hline & & Control & 15 & 5.6 & 2.0 & \\
\hline
\end{tabular}

\section{RESULTS}

\section{Psychological Functioning}

ANOVA did not reveal a significant difference between subjects with CLP and subjects without CLP in terms of state anxiety $(p>.05)$ or trait anxiety $(p>.05)$ as measured by the STAIC and the STAI. There were also no significant differences in scores between subjects with CLP and subjects without CLP as measured by the SEI and the RSE $(p>.05)$. However, participants with CLP reported a greater number of depressive symptoms, compared with participants without CLP, as measured by the CDI $(p<.01)$. ANOVA did not reveal any significant differences in the symptoms of depression reported by participants in the test and control group who completed the BDI $(p>.05)$. Participants with CLP reported greater behavioral problems, compared with participants without CLP, as measured by the YSR $(p<.001)$. However, for those participants who completed the YASR, there was no significant difference between those with CLP and those without CLP $(p>.05)$. Table 3 presents the mean scores, standard deviations, and significance levels for each of the questionnaires.

\section{Happiness with Facial Appearance}

An independent samples $t$ test demonstrated that participants with CLP were significantly less happy with their facial ap-

TABLE 4 Mean values and standard deviations for "happiness with facial appearance"

\begin{tabular}{lccc}
\hline Group & $n$ & Mean $(\mathrm{mm})$ & $S D$ \\
\hline CLP & 159 & 63.4 & 22.7 \\
Control & 113 & 70.6 & 16.6 \\
Total & 272 & 66.4 & 20.7 \\
\hline
\end{tabular}

pearance, compared with participants who did not have CLP $(t=-2.86, d f=270, p<.01)$. The mean values and standard deviations are presented in Table 4. An independent samples $t$ test showed there was no significant difference between males and females regarding happiness with facial appearance $(t=$ $1.50, d f=270, p=.13$ ). In addition, there was no significant difference between males with CLP and females with CLP in terms of their happiness with facial appearance $(t=1.57, d f$ $=159, p=.12$ ).

\section{Social Functioning}

Sixty-two percent of participants with CLP $(\mathrm{n}=99)$ reported having been teased, compared with $22 \%(\mathrm{n}=25)$ of participants without CLP (OR $=5.8$ with $95 \% \mathrm{CI}, 3.4$ to 10.0$)$. This difference was significant. Teasing/bullying was described as physical, verbal, or emotional in nature. Ten children with CLP (6\%) reported being physically hurt as a result of teasing/ bullying, compared with one child in the control group. The majority of teasing/bullying reported by participants with CLP was related to the subject's facial appearance (55\%) or speech (34\%). The remainder were teased about other issues, such as having an unusual name or lack of sporting ability (11\%). Teasing among participants who did not have CLP was related primarily to weight and height $(\mathrm{n}=22,88 \%)$, speech $(\mathrm{n}=3$, $12 \%)$, or lack of sporting ability $(\mathrm{n}=2,8 \%)$.

One hundred and eight subjects with CLP (68\%) were dissatisfied with a specific feature of their facial appearance. Of these subjects, $30 \%(\mathrm{n}=32)$ were unhappy with the appearance of their noses, $29 \%(n=31)$ were unhappy with the appearance of their lips, 24\% $(\mathrm{n}=26)$ were unhappy with their teeth, and $11 \%(\mathrm{n}=12)$ were unhappy with their scars. The remaining $6 \%$ of subjects $(n=7)$ were unhappy with the shape of their chins or faces in general or with the presence of acne. Twenty percent of subjects $(\mathrm{n}=23)$ in the control group also were unhappy with their facial appearance. Of 
those, the majority $(n=19)$ were unhappy with the appearance of their teeth and a small number were unhappy because of acne $(\mathrm{n}=4)$.

Fifteen percent of participants with CLP $(n=24)$ and $31 \%$ of subjects without CLP ( $\mathrm{n}=35$ ) were unhappy with aspects of their appearance other than their facial appearance. This related primarily to dissatisfaction with height or weight in both groups. Twenty-nine percent $(n=46)$ of participants with CLP would consider taking action to change their appearance in the future, with the majority of these participants wishing to change a feature related to their cleft. By contrast, $8 \%$ (n $=9$ ) of those in the non-CLP group desired a change in their appearance.

Eighteen percent $(n=29)$ of participants with CLP were dissatisfied with their speech, compared with $4 \%(n=5)$ of participants in the control group (OR $=4.8$ with $95 \%$ CI, 1.8 to 12.9$)$. This difference was significant.

\section{Multivariable Analyses}

There were six main outcomes of interest in this research: anxiety, depression, self-esteem, behavioral problems, happiness with facial appearance, and satisfaction with speech. To conduct multivariable analysis with six outcomes would generate multiple analyses, which by chance alone would produce some significant results. Therefore, the data set was reduced by conducting a principal components analysis (Fayers and Machin, 2001). Scores for behavioral problems were not available for 8- to 10-year-olds in this study, and therefore "behavioral problems" was treated as an outcome by itself. In addition, the data relating to satisfaction with speech was dichotomous in nature, and this also was treated as a separate outcome that was examined using binary logistic regression analysis.

To facilitate a principal components analysis of the outcomes, the scores for the questionnaires were combined according to the construct they measured. This was done by standardizing the scores for each questionnaire: Standard variable $=(x-\bar{x}) / s$, where $\bar{x}=$ mean of data, and $s=$ standard deviation.

Four variables were created from the standardized scores: state anxiety (comprising standardized scores for state anxiety from both the STAI and STAIC), trait anxiety (comprising standardized scores for trait anxiety for both the STAI and STAIC), depression (comprising standardized scores for the $\mathrm{CDI}$ and BDI), and self-esteem (comprising standardized scores for the SEI and RSE).

Factor analysis revealed one clear component consisting of state anxiety, trait anxiety, depression, and self-esteem. Table
5 displays the loadings from the component matrix. Happiness with facial appearance was a separate component. An unweighted factor was created by summing the scores on the four outcomes comprising component 1 in the factor analysis and then dividing by 4. Adjustment was made for the self-esteem measure, because originally, a positive score represented higher self-esteem on this measure. Once adjusted, higher scores represented greater problems or difficulties and lower scores represented fewer problems or difficulties. This resulted in the unweighted factor referred to as the 'psychological functioning' factor. Examination of the distribution of scores for this factor revealed one obvious outlier. This case was identified and was excluded from the remaining analysis for this outcome. Therefore, four outcomes were investigated further using multivariable analysis: psychological functioning (i.e., a factor comprising state anxiety, trait anxiety, depression, and self-esteem), behavioral problems, happiness with facial appearance, and satisfaction with speech. For the behavioral problems outcome, the sum of scores on the YSR and the YASR was calculated and then was divided by two to create one variable representing the participants' self-reports of behavioral problems.

To determine which independent variables were suitable for inclusion in the multivariable analyses, a series of independent samples $t$ tests, ANOVA, and Pearson's correlation coefficients were performed by examining the relationship between each outcome and the following independent variables: presence of CLP, age, gender, socioeconomic status, position in family, visibility of scar, previous family history of CLP, and experience of teasing. Independent variables were entered into the regression analyses only where they proved to be significant in the univariate analyses.

A history of teasing/bullying was a significant predictor of higher scores on the psychological functioning factor (i.e., having been teased resulted in poorer psychological functioning; Table 6). However, the presence of CLP per se did not significantly affect scores on this factor. Linear regression analysis demonstrated that older participants, females, and participants who had been teased had significantly greater behavioral problems (Table 7).

Linear regression analysis also demonstrated that having a visible scar, having been teased, and being older were predictors of unhappiness with facial appearance (Table 8). Binary logistic regression analysis determined that having CLP and being older were predictors of dissatisfaction with speech (Table 9).

\section{Discussion}

One of the main reasons for conducting this research was to address the deficit in our knowledge of the psychosocial

TABLE 5 Component matrix from factor analysis of outcomes

\begin{tabular}{lcccc}
\hline & State anxiety & Trait anxiety & Depression & $\begin{array}{c}\text { Happiness with facial } \\
\text { appearance }\end{array}$ \\
\hline Outcome & 0.827 & 0.862 & 0.751 & -0.772 \\
\hline
\end{tabular}


TABLE 6 Linear regression analysis for psychological functioning*

\begin{tabular}{|c|c|c|c|c|c|}
\hline & $\begin{array}{c}\text { Unstandardized } \\
\text { coefficients }\end{array}$ & $S E$ & $\begin{array}{l}\text { Standardized } \\
\text { coefficients }\end{array}$ & $t$ & Significance $p$ \\
\hline (Constant) & -0.284 & 0.087 & & -3.281 & .001 \\
\hline Teased/bullied & 0.475 & 0.100 & 0.304 & 4.741 & $<.001$ \\
\hline Presence of CLP & 0.134 & 0.101 & 0.085 & 1.320 & .188 \\
\hline
\end{tabular}

* Adjusted $r^{2}=.072$.

functioning of individuals with CLP. A key feature of this study was the inclusion of an examination of the self-reported experiences of individuals with CLP. A range of psychosocial outcomes was assessed to provide an in-depth analysis of individuals with CLP.

Subjects with CLP who completed the CDI reported more depressive symptoms than did subjects without CLP. No previous study has assessed the self-reports of depressive symptoms among children and young adults with CLP in comparison with a control group. Millard and Richman (2001) examined depression among a group of children with CLP, although comparisons were made across cleft types and not in relation to a control group. Therefore, these results represent an important first step in assessing depression among young people with CLP. There is some evidence from other areas of research that may help to explain why subjects with CLP have increased symptoms of depression. Reinherz et al. (1989) found that early physical illness was a risk factor for depressive symptoms in adolescence. It might be reasonable to speculate that children with CLP consider their condition to be an illness, which may partly explain the increased level of depressive symptoms.

Symptoms of depression in childhood and adolescence are of concern, because self-reported depressive symptoms in childhood have been found to predict psychiatric symptoms in young adulthood (Aronen and Soininen, 2000). Furthermore, early adolescent symptoms of depression have been linked to a subsequent increase in the risk of excessive alcohol consumption (Kumpulainen, 2000).

Behavioral problems were greater among adolescents with CLP than in control subjects, as assessed by the YSR. Behavioral problems often are seen as risk factors for developing other disorders. For example, internalizing behavior is considered to be a risk factor for developing anxiety disorders. Hofstra et al. (2001) found that high rates of behavioral problems during adolescence were risk factors for psychiatric disorders in adulthood. It has been suggested that parents with a child who has CLP may feel that they are in some way responsible for the condition and may overcompensate by failing to place appropriate limits on their child's bad behavior (Ludder-Jackson and Vessey, 1996).

Subjects with CLP were significantly less happy with their facial appearance than were subjects who did not have CLP. This is in accordance with previous findings by Kapp (1979) and Marcusson et al. (2002). During the interviews, the responses to questions concerning facial appearance clearly demonstrated that subjects with CLP had concerns regarding facial features specifically related to the condition, namely their noses, lips, teeth, and scars. Noar (1991) reported that 54\% of his sample of CLP patients were unhappy with specific aspects of their facial appearance. In the current study, $68 \%$ of subjects with CLP were unhappy with a specific aspect of their facial appearance. This greater dissatisfaction may reflect the increasing importance that society has placed on facial appearance and attractiveness in recent years.

Four main outcomes relative to the subjects' self-reports were investigated using multivariable analyses: psychological functioning, behavioral problems, happiness with appearance, and satisfaction with speech. Having been teased/bullied was a significant predictor of poor psychological functioning, greater behavioral problems, and unhappiness with facial appearance. Having CLP per se was not predictive of these outcomes. Therefore, it seems that it was the experience of being teased, rather than having CLP per se, that predicted greater psychosocial problems. However, further examination of the descriptive data for teasing and the presence of CLP reveals that those subjects who were teased most often were those who had CLP. This suggests that there is a complex interaction between the presence of CLP and the experience of teasing/bullying, and also that external factors may play a more dominant role in the level of psychosocial impairment than does the presence of the CLP itself.

In the current study, almost two thirds of those with CLP reported being teased/bullied. Of particular concern were re-

TABLE 7 Linear regression analysis for behavioral problems*

\begin{tabular}{|c|c|c|c|c|c|}
\hline & $\begin{array}{c}\text { Unstandardized } \\
\text { coefficients }\end{array}$ & $S E$ & $\begin{array}{c}\text { Standardized } \\
\text { coefficients }\end{array}$ & $t$ & Significance $p$ \\
\hline (Constant) & -1.179 & 0.353 & & -3.335 & .001 \\
\hline Age & 5.646 & 0.023 & 0.163 & 2.494 & .013 \\
\hline Gender & 0.343 & 0.133 & 0.171 & 2.584 & .011 \\
\hline Presence of CLP & -0.275 & 0.146 & -0.135 & -1.882 & .061 \\
\hline Teased/bullied & 0.606 & 0.141 & 0.304 & 4.295 & $<.001$ \\
\hline
\end{tabular}

* Adjusted $r^{2}=.187$. 
TABLE 8 Linear regression analysis for happiness with facial appearance*

\begin{tabular}{lccccc}
\hline & $\begin{array}{c}\text { Unstandardized } \\
\text { coefficients }\end{array}$ & SE & $\begin{array}{c}\text { Standardized } \\
\text { coefficients }\end{array}$ & $t$ & Significance $p$ \\
\hline (Constant) & 1.097 & 0.226 & & 4.850 & $<.001$ \\
Age & -0.0777 & 0.015 & -0.282 & -5.081 & $<.001$ \\
Visibility of scar & 0.259 & 0.121 & 0.125 & 2.141 & .03 \\
Teased/bullied & -0.483 & 0.119 & -0.241 & -4.068 & $<.001$ \\
\hline
\end{tabular}

$*$ Adjusted $r^{2}=.187$

ports by 11 subjects (10 with CLP, 1 without) that they had been physically bullied. Teasing/bullying is a serious issue for the young person in both the short- and long-term. Frequency of teasing is known to be associated positively with depressive symptoms, general anxiety, fear of negative evaluation, and loneliness (Storch et al., 2003). From a long-term perspective, research has found a relationship between anxiety disorders in adulthood and self-reported history of teasing or bullying experiences in childhood (McCabe et al., 2003). In light of these findings, it would be interesting to conduct further studies to examine the predictors of teasing. Future research could establish why some subjects with CLP are teased and others are not.

Age was a significant predictor for behavioral problems, happiness with facial appearance, and satisfaction with speech. Overall, older subjects had more behavioral problems and were less happy with their appearance and their speech than younger subjects were. This finding is important for those involved in caring for individuals with CLP. It is important for the health professional to be aware that adolescents may become less happy with their facial appearance as they get older, and this may influence their desire for further treatment. It also suggests that the burden of having CLP may be greater at some times than at others, and this may be expressed as behavioral difficulties in the home or the classroom.

The results of this research demonstrate the significance of cleft type in psychosocial functioning. The presence of a visible scar resulted in greater unhappiness with facial appearance. This is similar to the findings of Broder et al. (1994) and Thomas et al. (1997), who reported that subjects with visible defects expressed greater dissatisfaction with their appearance than subjects with nonvisible defects did. Furthermore, when the current data were examined using multiple regression analysis, having a visible scar was a strong predictor of unhappiness with facial appearance.

In Northern Ireland, all individuals with CLP are treated by the same centralized cleft team. It can be assumed that all of the cleft children in this study have been exposed to the same treatment processes and that they represent a uniform group of patients in terms of treatment experience. This research also represents the first time that the self-reports of depressive symptoms and behavioral problems among young children and adolescents with CLP have been compared with non-CLP controls. The only previous studies that assessed the self-reports of behavioral problems among subjects with CLP did not include a control group (Starr, 1980a, 1980b).

It would be incorrect to suggest that the results of this study indicate that all children with CLP need psychological help. However, many of the young people with CLP were teased and had higher reports of depressive symptoms, behavioral problems, and unhappiness with facial appearance than control subjects had. Previous research has found that psychological problems in childhood are predictive of similar problems in later life, so it is important that these problems are addressed. The results of the current study suggest that the experience of teasing/bullying in particular appears to have a detrimental effect on the young person's psychosocial functioning. It is clear that these young people need more help in dealing with teasing/bullying to ensure that it does not affect their psychological well-being.

The findings of this research suggest that the prevalence and type of teasing should form a major component of any psychological evaluation. As a starting point for providing psychological help for these children, the reported results suggest that, as a minimum, psychological assessment and intervention should be aimed at those children who are being teased/bullied because of their facial appearance or speech.

\section{REFERENCES}

Achenbach TM. Manual for the Youth Self Report and 1991 Profile. Burlington: University of Vermont, Department of Psychiatry; 1991.

Achenbach TM. Manual for the Young Adult Self-Report and Young Adult Behavior Checklist. Burlington: University of Vermont, Department of Psychiatry; 1997.

Aronen ET, Soininen M. Childhood depressive symptoms predict psychiatric problems in young adults. Can J Psychiatry. 2000;45:465-470.

Beck AT, Steer RA, Brown GK. Beck Depression Inventory Manual. San Antonio: The Psychological Corp.; 1996.

TABLE 9 Binary logistic regression analysis for satisfaction with speech*

\begin{tabular}{|c|c|c|c|c|c|c|}
\hline & $B$ & $S E$ & Wald & $d f$ & Significance $p$ & $\operatorname{Exp}(B)$ \\
\hline Presence of CLP & 1.533 & 0.504 & 9.241 & 1 & .002 & 4.630 \\
\hline Age & -0.110 & 0.052 & 4.503 & 1 & .034 & 0.896 \\
\hline Constant & 3.053 & 0.783 & 15.212 & 1 & .00 & 21.184 \\
\hline
\end{tabular}

$* \mathrm{~B}=$ coefficient of predictor variables; Wald $=$ Wald statistic. 
Bjornsson A, Agustsdottir S. A psychosocial study of Icelandic individuals with cleft lip or cleft lip and palate. Cleft Palate Craniofac J. 1987;24:152-157.

Bressman T, Sader R, Ravens-Sieberer U, Zeilhofer HF, Horch HH. Quality of life research in patients with cleft lip and palate: preliminary results. Mund Kiefer Gesichtschir. 1999;3:134-139.

Broder HL, Smith FB, Strauss RP. Effects of visible and invisible orofacial defects on self-perception and adjustment across developmental eras and gender. Cleft Palate Craniofac J. 1994;31:429-436.

Brown L, Alexander J. Self-Esteem Index: Examiner's Manual. Texas: Pro-ed; 1991.

Fayers PM, Machin D. Quality of Life: Assessment, Analysis and Interpretation. New York: Wiley; 2001.

Geier R, Wittstock C. Psychosocial studies of surgically treated adults with unilateral total lip-maxilla-palate clefts. Psychiatr Neurol Medizinische Psychol. 1986;38:656-661.

Harper DC, Richman LC. Personality profiles of physically impaired adolescents. J Clin Psychol. 1978;34:636-642.

Heller A, Rafman S, Zvagulis I, Pless IB. Birth defects and psychosocial adjustment. Am J Dis Child. 1985;139:257-263.

Hofstra MB, Van Der Ende J, Verhulst FC. Adolescents' self-reported problems as predictors of psychopathology in adulthood: 10-year follow up study. $\mathrm{Br}$ J Psychiatry. 2001;179:203-209.

Hunt O, Burden D, Hepper P, Johnston C. The psychosocial effects of cleft lip and palate: a systematic review. Eur J Orthod. 2005;27:274-285.

Kapp K. Self-concept of the cleft lip and or palate child. Cleft Palate J. 1979; 16:171-176.

Kovacs M. Children's Depression Inventory Manual. New York: Multi-Health Systems; 1992.

Kumpulainen K. Psychiatric symptoms and deviance in early adolescence predict heavy alcohol use 3 years later. Addiction. 2000;95:1847-1857.

Ludder-Jackson P, Vessey JA. Primary care of the child with a chronic condition. St. Louis: CV Mosby; 1996.

Marcusson A, List T, Paulin G, Akerlind I. Reliability of a multidimensional questionnaire for adults with treated complete cleft lip and palate. Scand $J$ Plast Reconstr. 2001;35:271-278.

Marcusson A, Paulin G, Ostrup L. Facial appearance in adults who had cleft lip and palate treated in childhood. Scand J Plast Reconstr. 2002;36:16-23.

McCabe RE, Anthony MM, Summerfeldt LJ, Liss A, Swinson RP. Preliminary examination of the relationship between anxiety disorders in adults and selfreported history of teasing or bullying experiences. Cogn Behav Ther. 2003; 32:187-193.
McWilliams BJ, Paradise LP. Educational, occupational, and marital status of cleft palate adults. Cleft Palate J. 1973;10:223-229.

Millard T, Richman LC. Different cleft conditions, facial appearance, and speech: relationship to psychological variables. Cleft Palate Craniofac J. 2001;38:68-75.

Noar JH. Questionnaire survey of attitudes and concerns of patients with cleft lip and palate and their parents. Cleft Palate Craniofac J. 1991;28:279-284.

Peter JP, Chinsky RR. Sociological aspects of cleft palate adults: marriage. Cleft Palate J. 1974;11:295-309.

Ramstad T, Otten E, Shaw WC. Psychosocial adjustment in Norwegian adults who had undergone standardized treatment of complete cleft lip and palate (part II self-reported problems and concerns with appearance). Scand J Plast Reconstr Surg. 1995;29:329-336.

Reinherz HZ, Stewart-Berghauer G, Pakiz B, Frost AK, Moeykens BA, Holmes WM. The relationship of early risk and current mediators to depressive symptomatology in adolescence. J Am Acad Child Psychiatry. 1989;28:942947.

Richman LC. Self-reported social, speech, and facial concerns and personality adjustment of adolescents with cleft lip and palate. Cleft Palate J. 1983;20: $108-112$.

Richman LC, Millard T. Brief report: cleft lip and palate: longitudinal behavior and relationships of cleft conditions to behavior and achievement. J Pediatr Psychol. 1997;22:487-494.

Rosenberg M. Society and the Adolescent Self-Image. Middletown, CT: Wesleyan University Press; 1989.

Speilberger CD. State-Trait Anxiety Inventory for Children-Professional Manual. Menlo Park, CA: Mind Garden; 1973.

Speilberger CD. State-Trait Anxiety Inventory for Adults. Menlo Park, CA: Mind Garden; 1983.

Starr P. Cleft type, age, sex differences in teenagers' ratings of their own behavior, self-esteem, and attitude toward clefting. Rehabil Lit. 1980a;41:177179.

Starr P. Facial attractiveness and behavior of patients with cleft lip and/or palate. Psychol Rep. 1980b;46:579-582.

Storch EA, Bravata EA, Storch JB, Johnson JH, Roth DA, Roberti JW. Psychosocial adjustment in early adulthood: the role of teasing and father support. Child Study J. 2003;33:153-163.

Thomas PT, Turner SR, Rumsey N, Dowell T, Sandy JR. Satisfaction with facial appearance among subjects affected by a cleft. Cleft Palate Craniofac J. 1997;34:226-231.

Wirls CJ, Plotkin RR. A comparison of children with cleft palate and their siblings on projective test personality factors. Cleft Palate J. 1971;8:399408. 